\title{
Comparison of a PWM Inverter and a Multilevel Inverter using the Switching Function Analysis for Harmonic Content and Efficiency
}

\author{
Dr. F. Paterakis \\ Technological Educational Institute \\ of Athens/ Department of Electronic \\ Engineering, Greece \\ fpatera@teiath.gr
}

\author{
Dr. C.C. Marouchos \\ Cyprus University of \\ Technology/Electrical Engineering, \\ Limassol, Cyprus \\ christos.marouchos@cut.ac.cy
}

\author{
Dr. M. Darwish \\ Brunel University/ \\ School of Engineering and Design, \\ London, UK \\ Mohamed.Darwish@brunel.ac.uk
}

\author{
Dr. D. Nafpaktitis \\ Technological Educational Institute \\ of Athens/ Department of Electronic \\ Engineering, Greece \\ dnafpaktitis@teiath.gr
}

\begin{abstract}
A conventional 3-level PWM Inverter and a Cascaded Multilevel Inverter, both rated at $230 V_{\text {rms }}$ voltage output and $3 \mathrm{KW}$ are analysed using the Switching Function. The PWM signal for the 3-level inverter is derived by applying the Switching Function Technique to the equal area principle. For the Cascaded Multilevel Inverter the Switching Function Technique is initially applied to each H-bridge, and then added to derive the overall Switching Function for the Multilevel Inverter output. A new technique is employed to derive the pulse width of each H-bridge converter in order to construct the output voltage. Voltage expressions of the output voltages are derived for both topologies. The switching frequency is chosen to be the same for both inverters. To ensure the same number of commutations over a fundamental cycle for both inverters, the levels of the Multilevel Inverter must be properly selected to meet the PWM frequency of the conventional inverter. Frequency spectrum and expressions of THD of the output voltage are derived. The two inverters are compared in terms of THD and harmonic content of the output voltage. The efficiency is concluded from the number of switching instances and other parameters of the circuit.
\end{abstract}

Index Terms - Equal Areas, Multilevel Inverter, PWM, Switching Function, THD

\section{INTRODUCTION}

Multilevel inverters have been received more and more attention for medium and high voltage applications providing a cost effective solution in the market [1]. Advantages such as high voltage operation, low switching losses, high efficiency, low electromagnetic interference (EMI) are the main reasons for their wide use in applications such as Grid connected PV systems, electric cars, (Flexible Alternating Current Transmission System) FACTS controllers and many others [2]. In contrast to the conventional 3-level full bridge Inverter, beside the low frequency content of the output voltage, their main disadvantage is the large amount of components both capacitors and semiconductor switches that are needed to achieve the staircase voltage output. One topology of Multilevel Inverter, where capacitors are eliminated is the Cascaded $\mathrm{H}$-Bridge Multilevel Inverter (CHB-MLI) but it needs separate dc sources [3], Fig. 1. This topology has gained wide research interest in Grid connected and standalone PV systems where separate dc sources are readily available [4-6]. While, in most power electronic converter circuits the voltage output is usually analyzed utilizing the Fourier series, the Switching Function analysis has been also used to obtain the outputs harmonic spectrum [7-9]. The use of the Switching Function technique on various power electronic converter circuits and for the traditional 3-Level H-Bridge PWM inverter, has been described extensively in [10].

In this paper both the Cascaded H-Bridge Multilevel Inverter (CHB-MLI) and the 3-Level Bridge Unipolar PWM are presented and analyzed using the Switching Function technique. For the determination of the pulse widths for both inverters the theory of equal area criteria is used [11-12]. The analysis focuses on the output voltage harmonics and it is shown that by applying the Switching Function technique their magnitude and order are readily available.

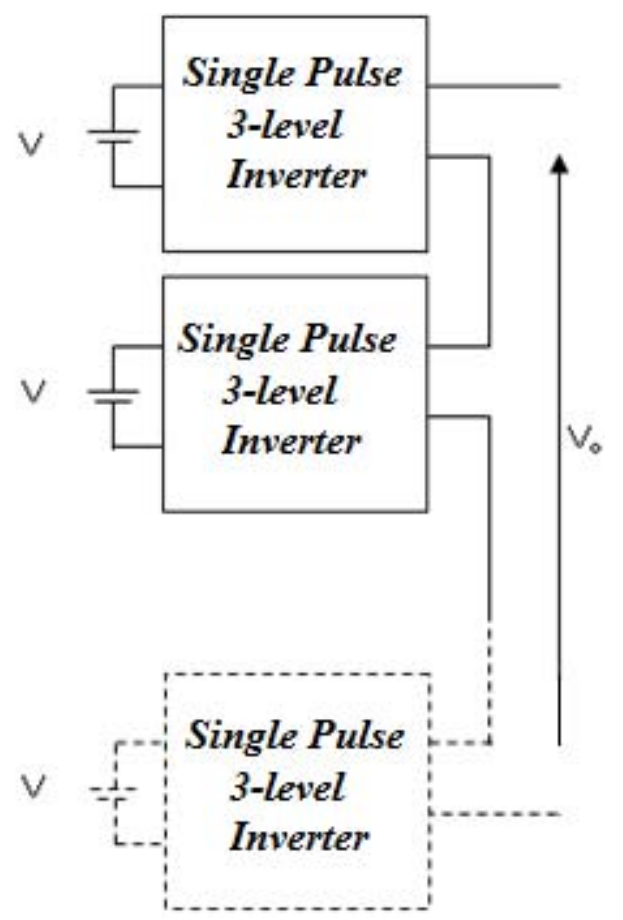

Fig. 1. Cascaded H-Bridge Multilevel Inverter (CHB-MLI) 


\section{ANALYSIS OF THE INVERTERS}

\section{A. The Switching Function Technique}

The switching function is defined [10] as the function which when it is multiplied with the input it gives the output (1).

$$
\mathrm{V}_{\mathrm{o}}(\mathrm{t})=\mathrm{F}(\mathrm{t}) \cdot \mathrm{V}_{\text {in }}(\mathrm{t})
$$

In this context there are two switching functions employed for the analysis of power electronic circuits. $F(t)$ is a series of pulses Fig. 2, of unity values described by (2)

$$
F(t)=K_{\mathrm{o}}+2 \sum_{n=1}^{\infty} \frac{\sin (n \delta)}{n \pi} \cos (n \omega t-n \theta)
$$

Where, $\quad \mathrm{n}$ is an integer number

$\mathrm{K}_{\mathrm{o}}=$ duty cycle of the pulse

$\delta=$ half the on period of the pulse

$\theta=$ phase delay

$\omega=$ switching frequency

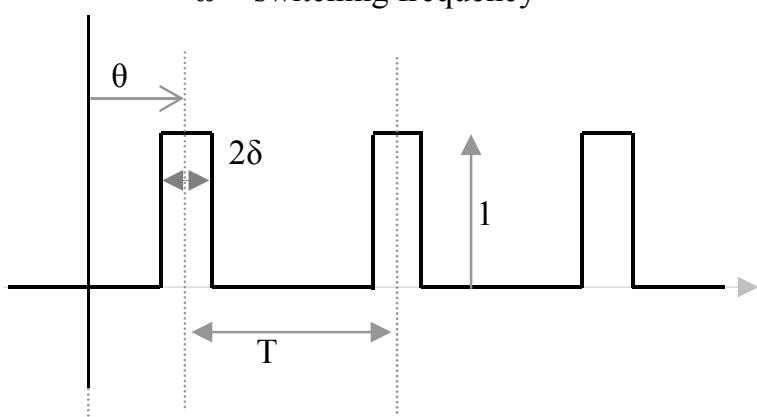

Fig. 2. The Switching Function $\mathrm{F}(\mathrm{t})$

The second switching function is a quasi-square signal Fig. 3, which is appropriate to describe the operation of a bridge circuit configuration (3).

$$
F_{B}(t)=4 \sum_{n=1}^{\infty} \frac{\sin (n \delta)}{n \pi} \cos (n \omega t-n \theta)
$$

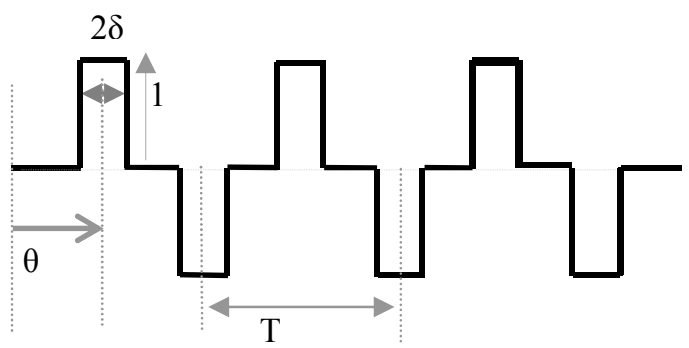

Fig. 3. The quasi-square signal switching function

\section{B. Unipolar PWM Using the Switching Function}

The Unipolar PWM signal is derived from Fig. 4.

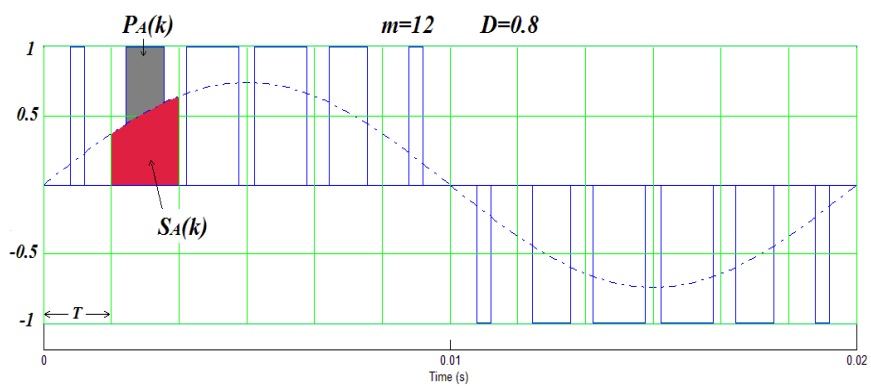

Fig. 4. Equal area Technique

A cycle of the voltage to be produced is divided into $m$ sectors, where each sector is $T$ seconds, Fig. 4. Therefore the switching frequency of the PWM signal is $1 / T$. In this case $m$ $=12$ so that the switching instances correspond to a 13-level Multilevel Inverter. The width of each pulse to form a PWM signal is calculated according to the equal areas technique. The area of the sector under the sine-wave $\mathrm{S}_{\mathrm{A}}(\mathrm{k})$ must be equal to the area $\mathrm{P}_{\mathrm{A}}(\mathrm{k})$ of a pulse height 1 ,

$$
\mathrm{P}_{\mathrm{A}}(\mathrm{k})=\mathrm{S}_{\mathrm{A}}(\mathrm{k})
$$

The width of the $k^{\text {th }}$ pulse is calculated from (4). For the purpose of the Switching Function application we need the half width $\delta$ and for the $k^{\text {th }}$ pulse it is derived from (4)

$$
\delta=\left[\frac{1}{2} \cdot[\cos [(k-1) \cdot T]-\cos (k \cdot T)] \cdot D\right]
$$

Where $D$ is the depth of modulation, $T$ is the duration in seconds of each of the $m$ sectors, setting the period of the PWM signal and $k$ is an integer number. For the last pulse in the half cycle, $k=m / 2$. The position of the center pulse is given by

$$
\theta=T \cdot k-\frac{T}{2}
$$

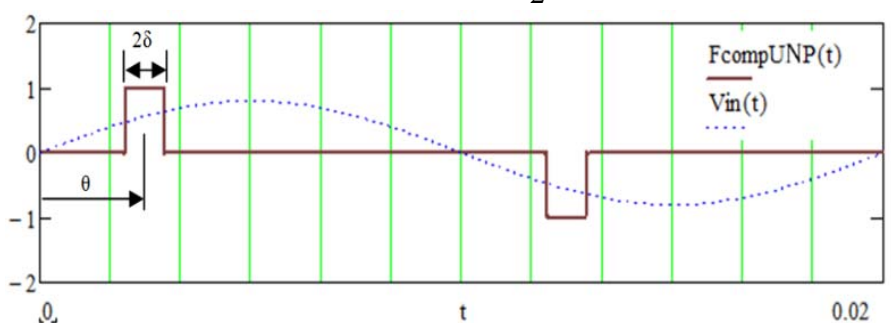

Fig. 5. The Single pulse switching function, $F_{\text {pulse }}(t)$

By considering the $k^{\text {th }}$ pulse in the positive half cycle and the corresponding pulse in the negative half cycle a Single pulse Switching Function is formed Fig. 5 and the expression for it is readily derived from (3) as

$$
F_{p u l s e}(t)=4 \sum_{n=1}^{\infty} \frac{\sin (n \delta)}{n \pi} \cos (n \omega t-n \theta)
$$

Where $\omega$ holds the switching frequency of the Single pulse Switching Function but also the frequency of the 
voltage to be produced and $n$ is an odd integer number giving the order of the harmonic in the signal.

Now the PWM signal is simply the summation of $m / 2$ Single pulse Switching Functions, each corresponding to a pulse in the cycle of the voltage to be produced.

$$
P W M_{U N I P}(t)=4 \sum_{k=1}^{k=m / 2} \sum_{n=1}^{\infty} \frac{\sin (n \delta)}{n \pi} \cos (n \omega t-n \theta)
$$

The output voltage, is given according to the definition of the switching function as

$$
V o(t)=P W M_{U N I P}(t) \cdot V d c
$$

Where Vdc is the dc input voltage to the inverter, Fig. 6.

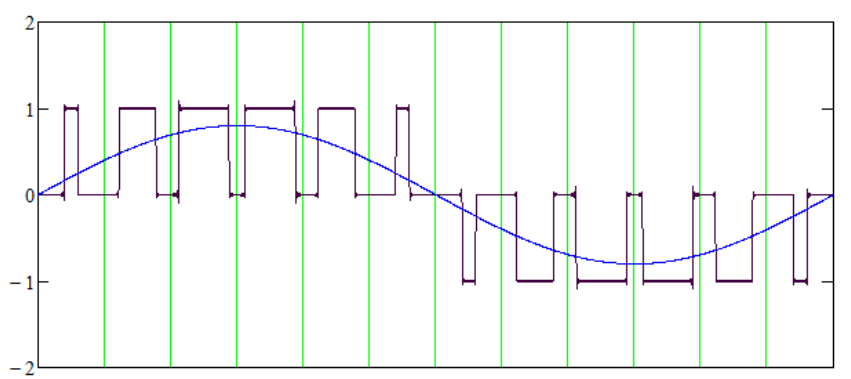

Fig. 6. The Unipolar Conversion PWM Function

For the harmonic content and Total Harmonic Distortion, the magnitudes of the $n^{\text {th }}$ harmonic $V_{o} P \operatorname{WM}_{U N I P}(n)$ in the output voltage are derived from the output voltage expression (9). Because each harmonic is built from the contributions of each cascaded inverter and it appears with a different phase (6), (9) must be resolved into in-phase and quadrature components and then added as vectors

$$
\begin{aligned}
& V_{o} P_{W M_{U N I P}}(n)= \\
& V d c \sqrt{\left[4 \sum_{k=1}^{k=m / 2} \sum_{n=1}^{\infty} \frac{\sin (n \delta)}{n \pi} \sin (\theta)\right]^{2}+} \\
& \sqrt[\left[4 \sum_{k=1}^{k=m / 2} \sum_{n=1}^{\infty} \frac{\sin (n \delta)}{n \pi} \cos (\theta)\right]^{2}]{ }
\end{aligned}
$$

The harmonic distortion (HD) is derived for the first 50 harmonics, as \%HD. The term \% THD is dropped in this case as it can be misleading.

$$
\% H D=\sqrt{\frac{\sqrt{\left(V o_{P W M_{U N I P}}(n)\right)^{2}}}{V O_{P W M_{U N I P}}(1)}}
$$

\section{Cascaded H Bridge Multilevel Inverter (CHB-MLI)}

A number of 3 level H-bridge inverters are connected in series, to form the stepped waveform of the output voltage, Fig. 7. The analysis is performed by employing the Switching Function. The output of each of the three 3-level $\mathrm{H}$-bridge inverter $V_{3 L H b}(t)$ is easily described by a employing the switching function (2) presented above as shown in Fig. 3 and repeated in Fig. 8.

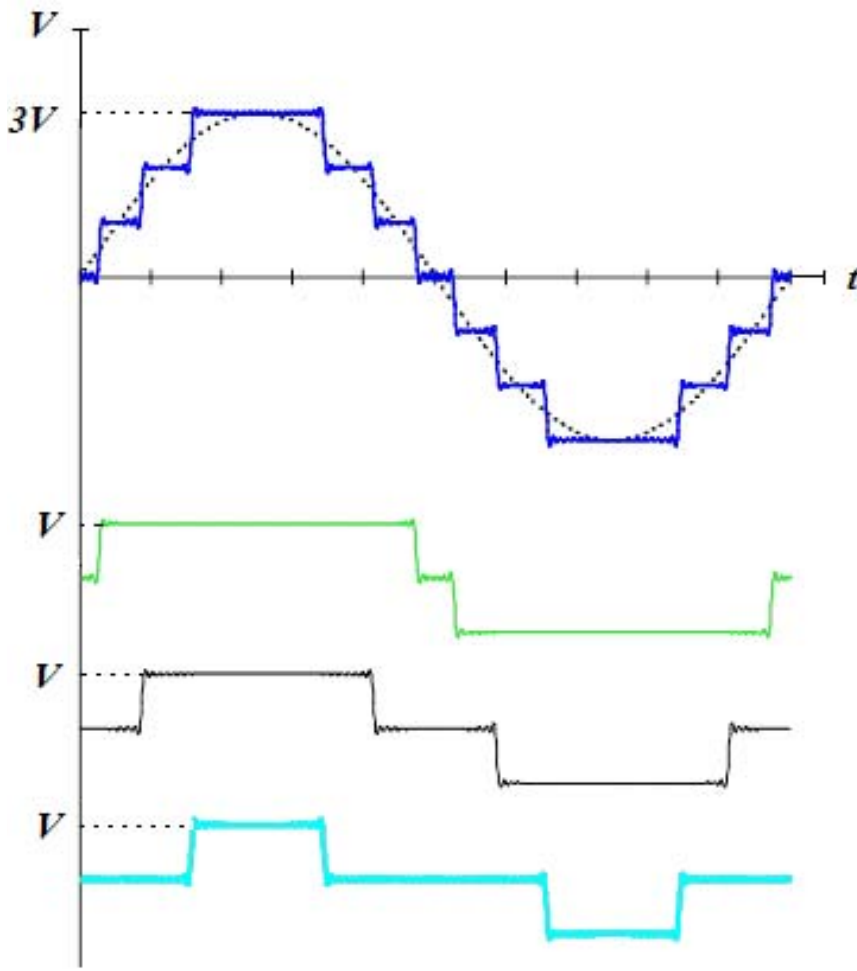

Fig. 7. Synthesis of the Output of a Cascaded H-Bridge Multilevel Inverter (CHB-MLI)

$$
V_{3 L H}(t)=4 V \sum_{n=1}^{\infty} \frac{\sin (n \delta)}{n \pi} \cos (n \omega t-n \theta)
$$

Where $\omega$ is the frequency of the voltage to be produced and $n$ is an odd integer number giving the order of the harmonic in the signal. $V$ is the voltage of the dc input to a single 3-level H-bridge inverter. The rest of the parameters are defined in section $A$. Now, the output voltage for the CHB-MLI is simply the sum of all the inverters outputs

$$
V o_{M L I}(t)=4 V \sum_{k=1}^{K} \sum_{n=1}^{\infty} \frac{\sin (n \delta)}{n \pi} \cos (n \omega t-n \theta)
$$

$K$ is the number of stacked 3-level H-bridge inverters, $\theta$ is $90^{\circ}$ and the rest of the parameters have been defined in section $A$, Fig. 9. 


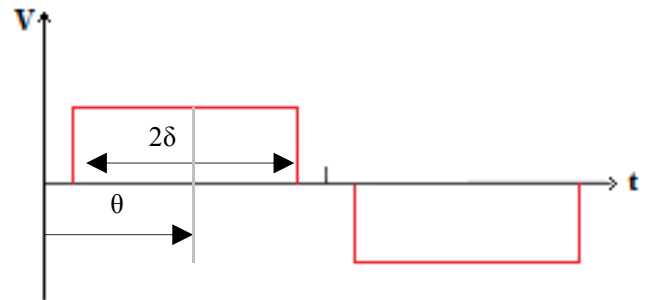

Fig. 8. The quasi-square signal switching function for each level of the Cascaded H Bridge Multilevel Inverter (CHB-MLI).

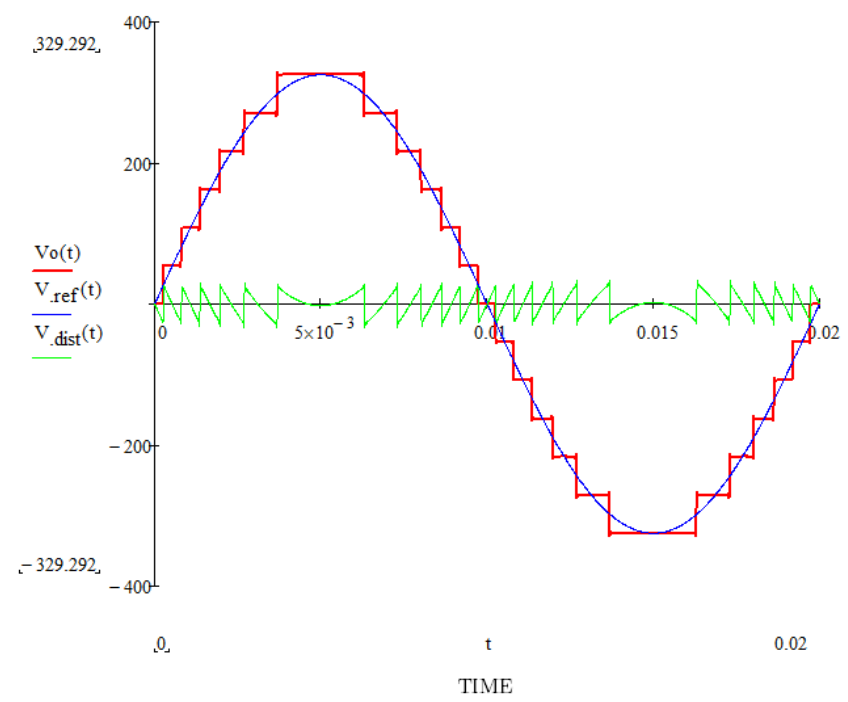

Fig. 9. Output of the Cascaded H Bridge Multilevel Inverter (CHB-MLI)

In order to minimize the output voltage harmonics, the width of each level is calculated in a similar way used for the PWM signal according to the equal areas criteria, Fig. 10.

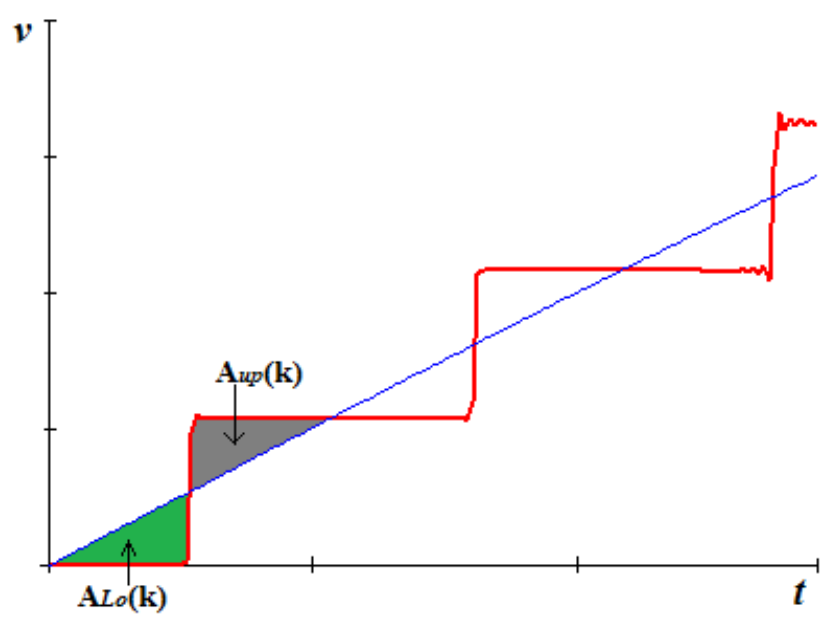

Fig. 10. The implementation of the equal areas technique.in CHB-MLI.

The point of intersection of the reference voltage and the output voltage is chosen so that the "upper" $\mathrm{A}_{\text {up }}(\mathrm{k})$ and the "lower" $\mathrm{A}_{\mathrm{Lo}}(\mathrm{k})$ triangle areas, are equal

$$
\mathrm{A}_{\mathrm{Lo}}(\mathrm{k})=\mathrm{A}_{\mathrm{up}}(\mathrm{k})
$$

In this application the reference voltage is considered as a straight line in the area of intersection and a simple formula is derived to find the width

$$
\delta(k)=\frac{\pi}{2}-a \sin \left[\frac{V(k-0.5)}{V p}\right]
$$

Where $V$ is the level of the output voltage of single 3 level H-bridge inverter, $V p$ is the peak value of the reference voltage and $k$ is an integer number indicating the corresponding level.

The magnitudes of all the harmonics in the output voltage are derived from the output voltage expression

$$
V O_{P W M_{M L I}}(n)=4 V \sum_{k=1}^{K} \sum_{n=1}^{\infty} \frac{\sin (n \delta)}{n \pi}
$$

And the magnitude of a single harmonic is

$$
V_{P W M_{M L I}(n)}=4 V \sum_{k=1}^{K} \frac{\sin (n \delta)}{n \pi}
$$

The harmonic distortion is derived again for the first 50 harmonics \%HD.

$$
\% \mathrm{HD}_{50}=\sqrt{\frac{\left(4 \sum_{n=2}^{50} V_{P W M_{M L I}}(n)\right)^{2}}{V_{P W M_{M L I}(1)}}}
$$

\section{THEORETICAL AND SIMULATION RESULTS}

For the PWM inverter the $230 \mathrm{~V}$ rms output is achieved with a dc input of $400 \mathrm{~V}$ and modulation index 0.83 . The frequency spectrum of the output voltage for the first 50 harmonics components is derived from (10) and it is shown in Fig. 11. The Harmonic distortion of the output voltage for the first 50 harmonics components is calculated from (19) as $73.98 \%$

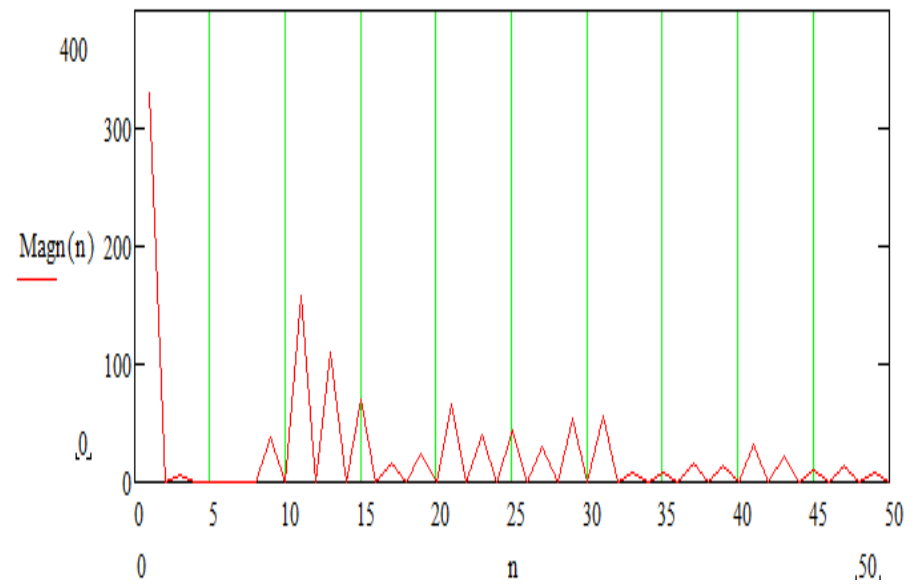

Fig. 11. Frequency Spectrum of the output voltage of the PWM inverter for the first $\mathrm{n}=50$ harmonics. 
For the Multilevel inverter the $230 \mathrm{~V}$ rms output is achieved with a single voltage level of $54 \mathrm{~V}$, Fig. 9. This corresponds to two PV modules in series per level. The frequency spectrum of the output voltage for the first 50 harmonics components is derived from (18) and it is shown in Fig. 12. The Harmonic distortion of the output voltage for the first 50 harmonics components is calculated from (19) as $5.285 \%$.

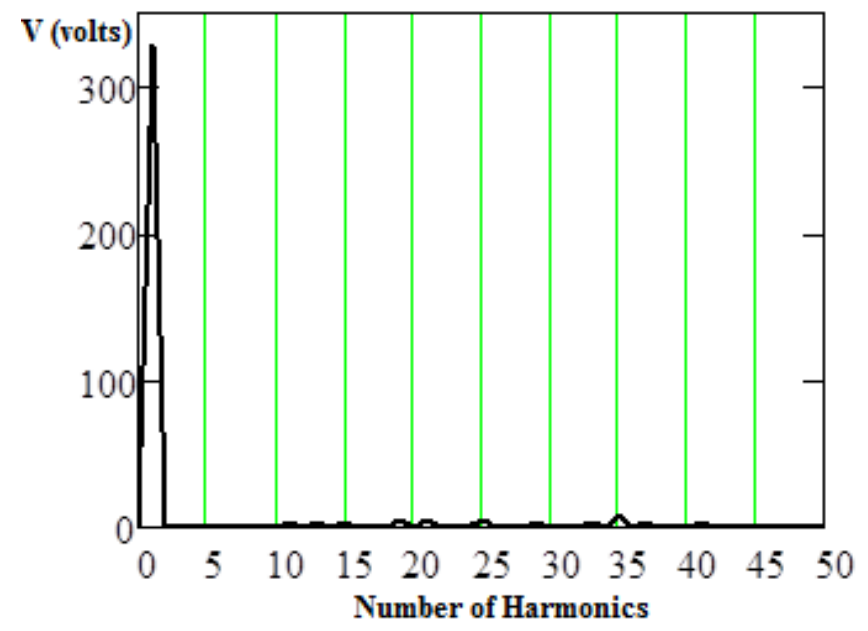

Fig. 12. Frequency Spectrum of the output voltage of the Multilevel Inverter for the first $\mathrm{n}=50$ harmonics.

\section{DISCUSSION}

The two inverters are both rated at $230 \mathrm{~V}$. One is modulated with a PWM signal and the other is a Multilevel Inverter based on the Cascaded H-Bridge topology. The switching frequency for both inverters is chosen to be the same applying 12 switching instances per cycle. This is to keep the overall losses, about the same for both inverters, providing a more clear comparison of the quality of the output voltages of each converter. The analysis of both, for the output voltage is performed by the Switching Function method of analysis. The equal area criteria are used for the determination of the pulse widths of both the PWM unipolar inverter and the Multilevel Inverter [11-12]. Expressions of the output voltage, the magnitude of each harmonic and the Harmonic Distortion for the first 50 harmonics are derived. The Harmonic Distortion for the first 50 frequency components of the Cascaded H Bridge Multilevel Inverter (CHB-MLI) is at $5.285 \%$ much lower than the PWM inverter which is $73.98 \%$.

Even though the switching frequency is the same for both inverters, the transistors in the PWM are switching a voltage which is six times higher than the Multilevel H-bridge suggesting that its switching losses are higher than the Multilevel. On the other hand in the Multilevel inverter the load current is flowing through numerous transistors during the cycle, adding to the static losses of the inverter. Therefore we can say with sufficient degree of confidence that the losses of the two inverters are comparable but we cannot suggest that the losses are the same unless a detailed analysis is done. In addition this paper demonstrated that the Switching Function analysis can be applied to Multilevel Inverters as well, providing a clear mathematical expression of the output for direct calculation of the harmonic content.

Nevertheless it is obvious that the Multilevel Inverter offers low harmonic distortion as compared to the PWM inverter at the cost of a high count of semiconductor devices.

\section{REFERENCES}

[1] J. Rodriguez, J.-S. Lai, and F. Z. Peng, "Multilevel inverters: A survey of topologies, controls, and applications," IEEE Trans. Ind. Electron., vol. 49, no. 4, pp. 724-738, Aug. 2002.

[2] L. G. Franquelo, J. Rodriguez, J. I. Leon, S. Kouro, R. Portillo, and M. A. M. Prats, "The age of multilevel converters arrives," IEEE Ind. Electron. Mag., vol. 2, no. 2, pp. 28-39, Jun. 2008.

[3] P. W. Hammond, "A new approach to enhance power quality for medium voltage AC drives,” IEEE Trans. Ind. Appl., vol. 33, no. 1, pp. 202-208, Jan./Feb. 1997

[4] E.Villanueva, P.Correa, J.Rodriguez, M.Pacas, "Control of a SinglePhase Cascaded H-Bridge Multilevel Inverter for Grid-Connected Photovoltaic Systems," IEEE Transactions on Industrial Electronics, vol.56, no.11, pp.4399-4406, Nov. 2009.

[5] S.Kouro, Bin Wu; Moya, E.Villanueva, P.Correa, J.Rodriguez, "Control of a cascaded H-bridge multilevel converter for grid connection of photovoltaic systems," Industrial Electronics, 2009. IECON '09. 35th Annual Conference of IEEE, vol., no., pp.3976-3982, 3-5 Nov. 2009.

[6] M. Y. Javed, Q. Ling, H. Rahman, Y. Saleem and M. M. Gulzar, "Design and implementation of a single-phase multilevel cascaded inverter for PV system," 2016 International Conference on Smart Grid and Clean Energy Technologies (ICSGCE), Chengdu, 2016, pp. 201206

[7] Marouchos, C.C, "Switched capacitor circuits for reactive power generation". PhD thesis, Department of Electrical Engineering and Electronics, Brunel University, UK, 1982

[8] Byoung-Kuk Lee and M. Ehsami, "A simplified functional simulation model for three-phase voltage-source inverter using switching function concept," in IEEE Transactions on Industrial Electronics, vol. 48, no. 2, pp. 309-321, Apr 2001.

[9] Jorma Kyyra, "Switching vector theory - unification of switching and space-vector theory in polyphase converter applications", Acta Polytechnica Scandinavica, Electrical Engineering Series, Vol. 83, 1995 , p. $2-164$

[10] C. C. Marouchos, "The Switching Function: analysis of power electronic circuits," in Circuits, Devices and Systems Series 17, London: Institution of Engineering and Technology, 2008

[11] Nafpaktitis, D., Paterakis, F., Darwish, M., Hloupis, G. (2016) 'The Equal Areas Pulse Width Modulation (EAPWM) Method: An alternative approach to programmed PWM schemes'. Journal of Electrical Systems, 12 (1). pp. 174 - 186.

[12] Paterakis, F., Nafpaktitis, D., Darwish, MK., Koulouras, G. , et al. (2016) 'Implementation of equal areas-PWM in multilevel inverters'. International Review of Electrical Engineering, 11 (6). pp. 558 - 566. doi: 10.15866/iree.v11i6.9812 